Research Paper

\title{
Sex Disparities in the Association of Lung Adenocar- cinoma with Colorectal Cancer
}

\author{
Zhi-Hong Jian" ${ }^{1}$, Chia-Chi Lung,1,2 Jing-Yang Huang ${ }^{1}$, Shih-Yung Su${ }^{1}$, Chien-Chang Ho ${ }^{3}$, Yi-Chen Chiang ${ }^{1,2}$, \\ and Yung-Po Liaw ${ }^{1,2}$ \\ 1. Department of Public Health and Institute of Public Health, Chung Shan Medical University, Taichung City 40201, Taiwan; \\ 2. Department of Family and Community Medicine, Chung Shan Medical University Hospital, Taichung City 40201, Taiwan; \\ 3. Department of Health and Leisure Management, Yuanpei University, Hsinchu City 300, Taiwan.
}

$\triangle$ Corresponding author: Yung-Po Liaw, Department of Public Health and Institute of Public Health, Chung Shan Medical University, No. 110, Sec. 1, Chien-Kuo N. Road, Taichung City 40201, Taiwan R.O.C. Phone: +88-642-4730022 ext.11838 Fax: +88-642-3248179 Email: Liawyp@csmu.edu.tw.

(ㅇ Ivyspring International Publisher. This is an open-access article distributed under the terms of the Creative Commons License (http://creativecommons.org/ licenses/by-nc-nd/3.0/). Reproduction is permitted for personal, noncommercial use, provided that the article is in whole, unmodified, and properly cited.

Received: 2013.07.26; Accepted: 2013.09.20; Published: 2013.11.02

\begin{abstract}
Background: Most cancers share common risk factors. It might provide evidence of shared risk factors with cancers by investigating cross-country and cross-township comparisons.

Methods: The data were obtained from International Association of Cancer Registries/World Health Organization and the National Cancer Registration Program of Taiwan. Age standardized incidence rates were calculated among gastric cancer, colorectal cancer and lung adenocarcinoma in 19 countries from 1995 to 1998. The Pearson correlations were also compared among 3 types of cancers for both sexes.

Results: The incidence rates of gastric and colorectal cancer throughout different countries show male dominance with a male-to-female sex ratio of around 2 and I.5, respectively. Significant cross-country correlations in colorectal cancer $(r=0.918, p<0.001)$, gastric cancer $(r=0.985$, $p<0.00 \mathrm{I})$ and lung adenocarcinoma $(r=0.685, p=0.00 \mathrm{I})$ were observed between men and women. There was a significant international correlation between colorectal cancer and lung adenocarcinoma in men $(r=0.526, p=0.021)$, but not in women. In cross-township comparisons of Taiwan, there were significant correlations in colorectal cancer $(r=0.45 \mathrm{I}, \mathrm{p}<0.00 \mathrm{I})$, gastric cancer $(r=0.486, p<0.001)$, and lung adenocarcinoma $(r=0.217, p<0.001)$ between men and women. There were links of lung adenocarcinoma and gastric cancer $(r=0.122, p=0.024)$ and colorectal cancer $(r=0.128, p=0.018)$ in women, and lung adenocarcinoma and colorectal cancer in men $(r=0.276, p<0.00 I)$.

Conclusions: There were associations between lung adenocarcinoma and colorectal cancer between and in both sexes in Taiwan, but not in cross-country comparisons. The results suggest that some factor, like genes, may be important as determinants for the association between lung adenocarcinoma and colorectal cancer.
\end{abstract}

Key words: Lung adenocarcinoma, Colorectal cancer, Pearson correlation.

\section{Introduction}

Despite an increasing cancer incidence in both genders, the effects of sex on colorectal cancer, lung cancer and gastric cancer incidence are well established and women are less likely to develop cancers than men $[1,2]$. In Taiwan, lung (ranked $1^{\text {st }}$ ), colorectal (ranked $3^{\text {rd }}$ ) and gastric (ranked $6^{\text {th }}$ ) cancers were the top 10 of most common cause of cancer death in 2011 [3]. Variable environmental exposures, life styles and comorbidities may contribute to these findings.

Comparisons of International Agency for Research on Cancer / World Health Organization (IARC/WHO) data showed that there were associa- 
tions between incidences of lung and colon cancers in men $[4,5]$. The incidences of cancers in colon and lung are higher in patients with diabetes [6]. Long-term use of statins was associated with increased risk colorectal and lung cancers [7]. The hormone replacement therapy also has been reported to be associated with reduced incidence of lung and colorectal cancer [8, 9]. In addition, the epidermal growth factor receptors (EGFR) are involved in the pathogenesis and prognostic significance of solid tumors such as cancers of the lung, colon, stomach, bladder, breast, and ovary $[10,11]$.The cancers of different body sites seem to correlate with one another. Finally, we examined our data to determine the cancer associations with sex disparities.

\section{Materials and Methods}

\section{Study Population}

We compared data through the National Cancer Registration Program in Taiwan and IARC/WHO from 1995 to 1998. The data for Taiwan were obtained directly from Office of Statistics, Department of Health in Taiwan. Since incidence rates for the under 30-year age group are often low, and rates for the over 80 -year group might be affected by competitive death effects and incomplete data, only rates for the age range 30 to 79 were enrolled to ensure adequate reliability of the estimates. The involved 19 countries were Australia, Canada, Denmark, England, Estonia, France, Iceland, India, Israel, Italy, Japan, The Netherlands, Poland, Singapore, Slovakia, Spain, Switzerland, United States and Taiwan. We compared age-standardized incidence rates (ASIR) among Taiwan and countries of WHO members. The significance of cross-township and cross-country correlations for gastric cancer, colon cancer and lung adenocarcinoma were evaluated for both sexes.

\section{Statistical Analysis}

ASIR were calculated by using world population for 1976 as the reference [12]. The significance of correlations among tumor types for cross-township and cross-country comparisons was evaluated with the SAS ver. 9.2 software package (SAS Institute, Cary, NC, USA). Correlation coefficients were generated by Pearson correlation coefficients, with $p<0.05$ considered to be significant.

\section{Results}

The ASIR from gastric cancer, colorectal cancer and lung adenocarcinoma per 100000 person-year in 19 countries from 1995 to 1998 are presented in Table 1. The highest incident rates were people in Japan for gastric cancer, men in Slovakia and women in Australia for colorectal cancer, and people in United States for lung adenocarcinoma. The range of male-female sex ratio among countries was 1.8 in India to 2.8 in France for gastric cancer, 1.1 in India to 1.9 in Slovkia for colorectal cancer, and 1.0 in Iceland to 4.7 in Spain for lung adenocarcinoma. These ratios remained relatively constant for gastric and colon cancer, but there were high varieties in sex ratio for lung adenocarcinoma.

Table I. Age standardized incidence rate in the age range 30 to 79 (per 100000 person year) from stomach and colorectal cancer, and lung adenocarcinoma in 19 countries, 1995-1998.

\begin{tabular}{|c|c|c|c|c|c|c|c|c|c|}
\hline \multirow[t]{2}{*}{ Country } & \multicolumn{3}{|c|}{ Colorectal cancer } & \multicolumn{3}{|c|}{ Gastric cancer } & \multicolumn{3}{|c|}{ Lung adenocarcinoma } \\
\hline & Male & Female & Ratio & Male & Female & Ratio & Male & Female & Ratio \\
\hline Australia & 98.0 & 65.5 & 1.5 & 19.4 & 8.3 & 2.3 & 21.9 & 10.8 & 2.0 \\
\hline Canada & 81.5 & 55.0 & 1.5 & 16.9 & 7.2 & 2.3 & 29.9 & 23.9 & 1.3 \\
\hline Denmark & 74.4 & 58.6 & 1.3 & 15.2 & 6.9 & 2.2 & 28.2 & 25.1 & 1.1 \\
\hline England & 77.1 & 48.4 & 1.6 & 28.0 & 10.9 & 2.6 & 16.7 & 11.2 & 1.5 \\
\hline Estonia & 65.9 & 42.2 & 1.6 & 68.3 & 29.8 & 2.3 & 10.6 & 3.2 & 3.3 \\
\hline France & 85.7 & 49.6 & 1.7 & 22.0 & 8.0 & 2.8 & 30.7 & 7.0 & 4.4 \\
\hline Iceland & 57.4 & 40.1 & 1.4 & 24.1 & 9.8 & 2.5 & 22.9 & 23.7 & 1.0 \\
\hline India & 11.4 & 9.8 & 1.1 & 17.7 & 9.6 & 1.8 & 4.2 & 2.0 & 2.1 \\
\hline Israel & 75.1 & 61.4 & 1.2 & 23.0 & 12.4 & 1.9 & 14.8 & 8.3 & 1.8 \\
\hline Italy & 85.9 & 55.1 & 1.6 & 45.2 & 22.7 & 2.0 & 34.4 & 8.4 & 4.1 \\
\hline Japan & 90.7 & 50.3 & 1.8 & 123.5 & 47.8 & 2.6 & 27.5 & 14.1 & 2.0 \\
\hline Netherlands & 90.3 & 60.8 & 1.5 & 29.3 & 10.8 & 2.7 & 26.3 & 9.1 & 2.9 \\
\hline Poland & 58.6 & 38.4 & 1.5 & 33.1 & 13.0 & 2.5 & 12.3 & 4.4 & 2.8 \\
\hline Singapore & 85.9 & 60.0 & 1.4 & 46.0 & 22.8 & 2.0 & 34.0 & 18.7 & 1.8 \\
\hline Slovakia & 101.3 & 52.3 & 1.9 & 42.3 & 17.2 & 2.5 & 16.0 & 4.1 & 3.9 \\
\hline Spain & 64.7 & 43.1 & 1.5 & 28.6 & 11.6 & 2.5 & 17.5 & 3.7 & 4.7 \\
\hline Switzerland & 66.0 & 41.2 & 1.6 & 19.1 & 9.3 & 2.1 & 26.1 & 14.5 & 1.8 \\
\hline United States & 77.1 & 54.8 & 1.4 & 14.8 & 6.3 & 2.3 & 39.5 & 29.4 & 1.3 \\
\hline Taiwan & 23.5 & 19.2 & 1.2 & 15.1 & 8.0 & 1.9 & 19.2 & 15.5 & 1.2 \\
\hline
\end{tabular}


Cross-country comparisons of cancers between men and women are present in Table 2a. Significant correlations in colorectal cancer, gastric cancer and lung adenocarcinoma were observed between men and women, with Pearson's correlation 0.918 $(p<0.001), 0.985(p<0.001)$ and $0.685(p=0.001)$, respectively. There was a positive correlation between lung adenocarcinoma in men and colorectal cancer in women $(\mathrm{r}=0.571, \mathrm{p}=0.011)$. The results for pairs of cancers in 19 countries are listed for men in Table $2 b$ and for women in Table 2c. There was a significant correlation between colorectal cancer and lung adenocarcinoma in men $(\mathrm{r}=0.526, \mathrm{p}=0.021)$, but not in women $(\mathrm{r}=0.278, \mathrm{p}=0.250)$.

Cross-township comparisons of cancers between Taiwanese men and women are showed in Table $3 \mathrm{a}$. There were significant correlations in colorectal cancer $(\mathrm{r}=0.451, \mathrm{p}<0.001)$, gastric cancer $(\mathrm{r}=0.486$, $\mathrm{p}<0.001)$ and lung adenocarcinoma $(\mathrm{r}=0.217, \mathrm{p}<0.001)$ between men and women. Significances between male colorectal cancer and female lung adenocarcinoma $(\mathrm{r}=0.280, \mathrm{p}<0.001)$, and male lung adenocarcinoma and female colorectal cancer $(\mathrm{r}=0.258, \mathrm{p}<0.001)$ were also observed. The results for significance of correlation coefficients for pairs of cancers in Taiwan are presented for men in Table $3 \mathrm{~b}$ and for women in Table 3c. There were links of lung adenocarcinoma and gastric cancer $(\mathrm{r}=0.122, \mathrm{p}=0.024)$ and colorectal cancer $(\mathrm{r}=0.128, \mathrm{p}=0.018)$ in women, and lung adenocarcinoma and colorectal cancer $(\mathrm{r}=0.276, \mathrm{p}<0.001)$ in men. There was a trend between cancers of stomach and colorectum in men, but it did not reach significance $(\mathrm{r}=0.101, \mathrm{p}=0.062)$.

Table 2a. Cross 19 country correlations of cancers between men and women.

\begin{tabular}{|c|c|c|c|}
\hline \multirow{2}{*}{$\begin{array}{l}\text { Site and tumor type } \\
\text { Male }\end{array}$} & \multicolumn{3}{|l|}{ Female } \\
\hline & Colorectum & Stomach & $\begin{array}{l}\text { Lung ade- } \\
\text { nocarcinoma }\end{array}$ \\
\hline \multicolumn{4}{|l|}{ Colorectum } \\
\hline $\mathrm{r}$ & 0.918 & 0.263 & 0.110 \\
\hline$p$ & $<0.001$ & 0.276 & 0.651 \\
\hline \multicolumn{4}{|l|}{ Stomach } \\
\hline $\mathrm{r}$ & 0.107 & 0.985 & -0.202 \\
\hline$p$ & 0.662 & $<0.001$ & 0.406 \\
\hline \multicolumn{4}{|l|}{$\begin{array}{l}\text { Lung adenocarcino- } \\
\text { ma }\end{array}$} \\
\hline $\mathrm{r}$ & 0.571 & 0.010 & 0.685 \\
\hline$p$ & 0.011 & 0.966 & 0.001 \\
\hline
\end{tabular}

Table 2b. Cross 19 country correlations between cancers in men.

\begin{tabular}{|c|c|c|c|}
\hline Site and tumor type & Colorectum & Stomach & $\begin{array}{l}\text { Lung adeno- } \\
\text { carcinoma }\end{array}$ \\
\hline \multicolumn{4}{|l|}{ Colorectum } \\
\hline $\mathrm{r}$ & 1 & 0.301 & 0.526 \\
\hline$p$ & & 0.209 & 0.021 \\
\hline \multicolumn{4}{|l|}{ Stomach } \\
\hline $\mathrm{r}$ & & 1 & 0.012 \\
\hline$p$ & & & 0.960 \\
\hline \multicolumn{4}{|l|}{$\begin{array}{l}\text { Lung adenocarcino- } \\
\text { ma }\end{array}$} \\
\hline $\mathrm{r}$ & & & 1 \\
\hline$p$ & & & \\
\hline
\end{tabular}

Table 2c. Cross 19 country correlations between cancers in women.

\begin{tabular}{|c|c|c|c|}
\hline Site and tumor type & Colorectum & Stomach & $\begin{array}{l}\text { Lung adeno- } \\
\text { carcinoma }\end{array}$ \\
\hline \multicolumn{4}{|l|}{ Colorectum } \\
\hline $\mathrm{r}$ & 1 & 0.095 & 0.278 \\
\hline$p$ & & 0.700 & 0.250 \\
\hline \multicolumn{4}{|l|}{ Stomach } \\
\hline $\mathrm{r}$ & & 1 & -0.216 \\
\hline$p$ & & & 0.374 \\
\hline \multicolumn{4}{|l|}{$\begin{array}{l}\text { Lung adenocarcino- } \\
\text { ma }\end{array}$} \\
\hline $\mathrm{r}$ & & & 1 \\
\hline$p$ & & & \\
\hline
\end{tabular}

Table 3a. Cross 346 township correlations of cancers between male and female Taiwanese.

\begin{tabular}{|c|c|c|c|}
\hline Site and tumor type & & & Female \\
\hline Male & Colorectum & Stomach & $\begin{array}{l}\text { Lung adenocar- } \\
\text { cinoma }\end{array}$ \\
\hline \multicolumn{4}{|l|}{ Colorectum } \\
\hline $\mathrm{r}$ & 0.451 & -0.035 & 0.280 \\
\hline$p$ & $<0.001$ & 0.518 & $<0.001$ \\
\hline \multicolumn{4}{|l|}{ Stomach } \\
\hline $\mathrm{r}$ & -0.027 & 0.486 & -0.045 \\
\hline$p$ & 0.616 & $<0.001$ & 0.402 \\
\hline \multicolumn{4}{|l|}{$\begin{array}{l}\text { Lung adenocarcino- } \\
\text { ma }\end{array}$} \\
\hline $\mathrm{r}$ & 0.258 & -0.007 & 0.217 \\
\hline$p$ & $<0.001$ & 0.902 & $<0.001$ \\
\hline
\end{tabular}

Table 3b. Cross 346 township correlations between cancers in male Taiwanese.

\begin{tabular}{|c|c|c|c|}
\hline Site and tumor type & Colorectum & Stomach & $\begin{array}{l}\text { Lung adeno- } \\
\text { carcinoma }\end{array}$ \\
\hline \multicolumn{4}{|l|}{ Colorectum } \\
\hline $\mathrm{r}$ & 1 & -0.035 & 0.276 \\
\hline$p$ & & 0.512 & $<0.001$ \\
\hline \multicolumn{4}{|l|}{ Stomach } \\
\hline $\mathrm{r}$ & & 1 & 0.101 \\
\hline$p$ & & & 0.062 \\
\hline \multicolumn{4}{|l|}{$\begin{array}{l}\text { Lung adenocarcino- } \\
\text { ma }\end{array}$} \\
\hline $\mathrm{r}$ & & & 1 \\
\hline$p$ & & & \\
\hline
\end{tabular}


Table 3c. Cross 346 township correlations between cancers in female Taiwanese.

\begin{tabular}{|c|c|c|c|}
\hline Site and tumor type & Colorectum & Stomach & $\begin{array}{l}\text { Lung adenocar- } \\
\text { cinoma }\end{array}$ \\
\hline \multicolumn{4}{|l|}{ Colorectum } \\
\hline $\mathrm{r}$ & 1 & 0.020 & 0.128 \\
\hline$p$ & & 0.717 & 0.018 \\
\hline \multicolumn{4}{|l|}{ Stomach } \\
\hline $\mathrm{r}$ & & 1 & 0.122 \\
\hline$p$ & & & 0.024 \\
\hline \multicolumn{4}{|l|}{$\begin{array}{l}\text { Lung adenocarcino- } \\
\text { ma }\end{array}$} \\
\hline $\mathrm{r}$ & & & 1 \\
\hline$p$ & & & \\
\hline
\end{tabular}

\section{Discussion}

We found that the sex ratio in cancers varied geographically. The incidences of gastric and colorectal cancer throughout different populations show male dominance with a constant male-to-female ratio. This sex ratio cannot be completely attributed to the disparities in the prevalence of known risk factors between the sexes [13, 14]. Recent advances in the molecular biology of gastric and colorectal cancer have led to greater understanding of the effect of estrogen in carcinogenesis. Estrogen has a potentially protective effect against the development of colorectal cancer [15] and invasions of gastric cancer [16], and may be the cause of improved prognosis of colorectal cancer in premenopausal women [17]. Also, women on hormone replacement therapy seem to have a decreased risk of gastric and colorectal cancer [18]. However, use of tamoxifen, an antagonist of the estrogen receptor, in women seems to increase their risk of gastric cancer [19].

Moore et al. conducted cross-country comparisons for cancer incidence in men $[4,5]$ and concluded that some factors could be involved in the association between lung adenocarcinoma and colorectal cancer. Cigarette smoke contains many carcinogens, and the gastrointestinal tracts are exposed to these compounds through the circulation or direct ingestion of saliva [20]. The relationships between smoking and increased risks of gastric and colorectal cancer have been established [21, 22]. However, few studies examining the effects of passive smoke exposure on risk of gastric cancer report inconsistent results [23, 24]. Passive smoke exposure on risk of colorectal cancer shows no association among women [25]. In Taiwan, lung adenocarcinoma and colorectal cancer were correlated in both sexes and between sexes, but not in the cross-country comparisons. Most of the female lung cancer patients in Taiwan were non-smokers and the proportion was more than $90 \%$ [8]. The relationship with passive smoking and smoking might be limited and incompatible with the observed association between lung adenocarcinoma and colorectal cancer so that other factors must be operating.

Obesity and overweight have become a global problem in the last decade. Given its documented promoting effects on colon carcinogenesis, insulin resistance and hyperinsulinaemia are certainly key biological mechanisms involving in tumor development [26]. The data from Taiwan National Health Insurance showed that the incidences of the most common cancers, such as liver, colon, lung, and prostate cancer increased independently in diabetic patients with hypertension, dyslipidemia, and gout [6]. Use of insulin was also reported to be associated with higher risks for liver, colorectal, lung, stomach, and pancreas cancer in type 2 diabetes in Taiwan [27]. The use of anti-diabetes drugs also has been reported to decrease the risk of lung cancer in diabetes patients [28]. Insulin resistance might play a role in the association between lung adenocarcinoma and colorectal cancer in Taiwanese, but it was not consistent with cross-country comparisons.

In Taiwan, the incidence of lung cancer is increasing and lung adenocarcinoma is the most common histological subtypes of lung cancer [29]. Among lung cancer patients without traditional risk factors, a substantial proportion of patients are found to have oncogene-driven malignancies, such as EGFR. It has been reported that mutations in genes encoding EGFR pathway proteins result in multiple aberrations in the signal-transduction pathways and dysregulation of the tyrosine kinase activity, and lead to tumor cell proliferation, inhibition of apoptosis, and dissemination [30]. More than $60 \%$ of non-small-cell lung cancers show EGFR overexpression [31], which is negatively prognostic [32]. The frequency of tumor EGFR mutations was found to be higher in East Asian ethnicity, such as Taiwan $[33,34]$.

Luo et al. found that multiple primary malignancies occurred more frequently in patients with lung adenocarcinoma and classic EGFR mutation [35]. Amplification and overexpression of EGFR also have been involved in development of numerous types of human cancer [36]. EGFR is widely expressed in colonic tissues and EGFR genes have gender-specific prognostic significance in colon cancer [37]. Wang et al. reported that low EGFR expression in patients with colorectal cancer was associated with low tumor metastasis and better survival [38]. Besides, amplification or overexpression of EGFR is present in gastric carcinomas with independent prognostic value [39, 40]. EGFR mutations and overexpression have been intensely pursued as extremely valuable for treatment of lung adenocarcinoma patients in Asian countries 
including Taiwan, where the EGFR mutation rate is higher than in the rest of the world.

One of the strengths of our study was the use of registered database, which was population-based and highly representative. A number of important limitations warrant discussion. First, we did not obtain basic information on smoking rate, air pollution, physical inactivity, incidence of diabetes, and dietary habits and rate of Helicobacter pylori infection. Second, as a result of modernization and life style changes globally, the incidence of the studied countries may have changed. The results from data collected between 1995 and 1998 could be established as a reference or model to which future studies could compare.

\section{Conclusions}

International and cross-township comparisons of tumor incidences can provide information on risk factors shared by different tissue sites. The main finding of our study is that link between lung adenocarcinoma and colorectal cancers may be associated with the increased risk in adenocarcinoma. To find shared candidate genes will lead to an understanding of the genetic associations and sex disparities among cancers, the development of more effective treatments, and better guiding future risk-stratification efforts, especially Taiwanese susceptible to adenocarcinoma.

\section{Abbreviations}

ASIR: Age-standardized incidence rates; EGFR, epidermal growth factor receptors; IARC/WHO: International Agency for Research on Cancer / World Health Organization.

\section{Acknowledgements}

We are extremely grateful to all persons who contributed to the data of International Association of Cancer Registries/World Health Organization and the National Cancer Registration Program of Taiwan. This manuscript does not necessarily reflect the opinions or views of WHO or the Department.

\section{Authors' contributions}

YPL was responsible for designing the study. $\mathrm{ZHJ}$ was responsible for drafting the manuscript. CCL, JYH, SYS, CCH and YCC did the statistical programming and helped with manuscript revisions. All authors read and approved the final manuscript.

\section{Competing Interests} interests.

\section{References}

1. Chen TA, Kang HY, Chang HC, Lin WC, Chao TM, Horng JT. Gender differences in colorectal cancer during the past 20 years in Taiwan. Int J Colorectal Dis. 2012; 27: 345-53. doi:10.1007/s00384-011-1318-1.

2. Chiang CJ, Chen YC, Chen CJ, You SL, Lai MS. Cancer trends in Taiwan. Jpn J Clin Oncol. 2010; 40: 897-904. doi:10.1093/jjco/hyq057.

3. [Internet] Deaprtment of Health. The publications of Department of Health, Executive Yuan, Taiwan 2011. http://www.mohw.gov.tw/cht/DOS/

4. Moore MA, Kunimoto T, Park CB, Tsuda H. Cross-country comparisons suggest shared risk factors for carcinomas, including male lung adenocarcinoma and colon cancer development. Lung cancer. 1999; 24: 149-55.

5. Moore MA, Kunimoto T, Park CB, Takasuka N, Tsuda H. European country comparisons provide evidence of a link between colon cancer and adenocarcinoma development in the lung but not the oesophagus. Eur J Cancer Prev. 1998; 7: 473-8.

6. Lee MY, Lin KD, Hsiao PJ, Shin SJ. The association of diabetes mellitus with liver, colon, lung, and prostate cancer is independent of hypertension, hyperlipidemia, and gout in Taiwanese patients. Metabolism. 2012; 61: 242-9. doi:10.1016/j.metabol.2011.06.020.

7. Vinogradova Y, Coupland C, Hippisley-Cox J. Exposure to statins and risk of common cancers: a series of nested case-control studies. BMC cancer. 2011; 11: 409. doi:10.1186/1471-2407-11-409.

8. Chen KY, Hsiao CF, Chang GC, Tsai YH, Su WC, Perng RP, et al. Hormone replacement therapy and lung cancer risk in Chinese. Cancer. 2007; 110: 1768-75. doi:10.1002/cncr.22987.

9. Rennert G, Rennert HS, Pinchev M, Lavie O, Gruber SB. Use of hormone replacement therapy and the risk of colorectal cancer. J Clin Oncol. 2009; 27: 4542-7. doi:10.1200/jco.2009.22.0764.

10. Nicholson RI, Gee JM, Harper ME. EGFR and cancer prognosis. Eur J Cancer. 2001; 37 Suppl 4: S9-15.

11. Salomon DS, Brandt R, Ciardiello F, Normanno N. Epidermal growth factor-related peptides and their receptors in human malignancies. Crit Rev Oncol Hematol. 1995; 19: 183-232.

12. Waterhouse JAH, Muir C, Correa P, Powell J. Cancer incidence in five continents. Lyon, IARC: IARC Scientific Publications; 1976.

13. Kelley JR, Duggan JM. Gastric cancer epidemiology and risk factors. J Clin Epidemiol. 2003; 56: 1-9.

14. Chan AT, Giovannucci EL. Primary prevention of colorectal cancer. Gastroenterology. 2010; 138: 2029-43 e10. doi:10.1053/j.gastro.2010.01.057.

15. Wilkins HR, Doucet K, Duke V, Morra A, Johnson N. Estrogen prevents sustained COLO-205 human colon cancer cell growth by inducing apoptosis, decreasing c-myb protein, and decreasing transcription of the anti-apoptotic protein bcl-2. Tumour Biol. 2010; 31: 16-22. doi:10.1007/s13277-009-0003-2.

16. Ryu WS, Kim JH, Jang YJ, Park SS, Um JW, Park SH, et al. Expression of estrogen receptors in gastric cancer and their clinical significance. J Surg Oncol. 2012. doi:10.1002/jso.23097.

17. Koo JH, Jalaludin B, Wong SK, Kneebone A, Connor SJ, Leong RW. Improved survival in young women with colorectal cancer. Am J Gastroenterol. 2008; 103: 1488-95. doi:10.1111/j.1572-0241.2007.01779.x.

18. Green J, Czanner G, Reeves G, Watson J, Wise L, Roddam A, et al. Menopausal hormone therapy and risk of gastrointestinal cancer: nested case-control study within a prospective cohort, and meta-analysis. Int J Cancer. 2012; 130: 2387-96. doi:10.1002/ijc.26236.

19. Camargo MC, Goto Y, Zabaleta J, Morgan DR, Correa P, Rabkin CS. Sex hormones, hormonal interventions, and gastric cancer risk: a meta-analysis. Cancer Epidemiol Biomarkers Prev. 2012; 21: 20-38. doi:10.1158/1055-9965.epi-11-0834.

20. Giovannucci E. An updated review of the epidemiological evidence that cigarette smoking increases risk of colorectal cancer. Cancer Epidemiol Biomarkers Prev. 2001; 10: 725-31.

21. Leufkens AM, Van Duijnhoven FJ, Siersema PD, Boshuizen HC, Vrieling A, Agudo A, et al. Cigarette smoking and colorectal cancer risk in the European Prospective Investigation into Cancer and Nutrition study. Clin Gastroenterol Hepatol. 2011; 9: 137-44. doi:10.1016/j.cgh.2010.10.012.

22. Ladeiras-Lopes R, Pereira AK, Nogueira A, Pinheiro-Torres T, Pinto I, Santos-Pereira R, et al. Smoking and gastric cancer: systematic review and meta-analysis of cohort studies. Cancer causes control. 2008; 19: 689-701. doi:10.1007/s10552-008-9132-y.

23. Duan L, Wu AH, Sullivan-Halley J, Bernstein L. Passive smoking and risk of oesophageal and gastric adenocarcinomas. Br J Cancer. 2009; 100: 1483-5. doi:10.1038/sj.bjc.6605023.

24. Mao Y, Hu J, Semenciw R, White K. Active and passive smoking and the risk of stomach cancer, by subsite, in Canada. Eur J Cancer Prev. 2002; 11: 27-38.

25. Paskett ED, Reeves KW, Rohan TE, Allison MA, Williams CD, Messina CR, et al. Association between cigarette smoking and colorectal cancer in the Women's Health Initiative. J Natl Cancer Inst. 2007; 99: 1729-35. doi:10.1093/jnci/djm176.

26. Becker S, Dossus L, Kaaks R. Obesity related hyperinsulinaemia and hyperglycaemia and cancer development. Arch Physiol Biochem. 2009; 115: 86-96. doi:10.1080/13813450902878054

27. Chang $\mathrm{CH}$, Lin JW, Wu LC, Lai MS, Chuang LM. Oral insulin secretagogues, insulin, and cancer risk in type 2 diabetes mellitus. J Clin Endocrinol Metab. 2012; 97: E1170-5. doi:10.1210/jc.2012-1162. 
28. Lai SW, Liao KF, Chen PC, Tsai PY, Hsieh DP, Chen CC. Antidiabetes drugs correlate with decreased risk of lung cancer: a population-based observation in taiwan. Clin Lung Cancer. 2012; 13: 143-8. doi:10.1016/j.cllc.2011.10.002.

29. Perng DW, Perng RP, Kuo BI, Chiang SC. The variation of cell type distribution in lung cancer: a study of 10,910 cases at a medical center in Taiwan between 1970 and 1993. Jpn J Clin Oncol. 1996; 26: 229-33.

30. Nelson V, Ziehr J, Agulnik M, Johnson M. Afatinib: emerging next-generation tyrosine kinase inhibitor for NSCLC. Onco Targets Ther. 2013; 6: 135-43. doi:10.2147/ott.s23165.

31. Gazdar AF. Epidermal growth factor receptor inhibition in lung cancer: the evolving role of individualized therapy. Cancer Metastasis Rev. 2010; 29: 37-48. doi:10.1007/s10555-010-9201-z.

32. Meert AP, Martin B, Verdebout JM, Noel S, Ninane V, Sculier JP. Is there a relationship between c-erbB-1 and c-erbB-2 amplification and protein overexpression in NSCLC? Lung cancer. 2005; 47: 325-36. doi:10.1016/j.lungcan.2004.07.047.

33. Shigematsu H, Lin L, Takahashi T, Nomura M, Suzuki M, Wistuba II, et al. Clinical and biological features associated with epidermal growth factor receptor gene mutations in lung cancers. J Natl Cancer Inst. 2005; 97: 339-46. doi:10.1093/jnci/dji055.

34. Huang SF, Liu HP, Li LH, Ku YC, Fu YN, Tsai HY, et al. High frequency of epidermal growth factor receptor mutations with complex patterns in non-small cell lung cancers related to gefitinib responsiveness in Taiwan. Clin Cancer Res. 2004; 10: 8195-203. doi:10.1158/1078-0432.ccr-04-1245.

35. Luo YH, Ho HL, Tsai CM, Shih JF, Chiu CH, Lai SL, et al. The Association Between Tumor Epidermal Growth Factor Receptor (EGFR) Mutation and Multiple Primary Malignancies in Patients With Adenocarcinoma of the Lungs. Am J Clin Oncol. 2013. doi:10.1097/COC.0b013e318292f88c.

36. Hynes NE, Lane HA. ERBB receptors and cancer: the complexity of targeted inhibitors. Nat Rev Cancer. 2005; 5: 341-54. doi:10.1038/nrc1609.

37. Press OA, Zhang $W$, Gordon MA, Yang $D$, Lurje $G$, Iqbal $S$, et al. Gender-related survival differences associated with EGFR polymorphisms in metastatic colon cancer. Cancer Res. 2008; 68: 3037-42. doi:10.1158/0008-5472.can-07-2718.

38. Wang WS, Chen PM, Chiou TJ, Liu JH, Lin JK, Lin TC, et al. Epidermal growth factor receptor R497K polymorphism is a favorable prognostic factor for patients with colorectal carcinoma. Clin Cancer Res. 2007; 13: 3597-604. doi:10.1158/1078-0432.ccr-06-2601.

39. Geng Y, Chen X, Qiu J, Zhou Y, Wang J, Liu L, et al. Human epidermal growth factor receptor-2 expression in primary and metastatic gastric cancer. Int J Clin Oncol. 2013; doi:10.1007/s10147-013-0542-9.

40. Jørgensen JT, Hersom M. HER2 as a prognostic marker in gastric cancer - a systematic analysis of data from the literature. J Cancer. 2012; 3: 137-44. doi: $10.7150 /$ jca.4090 